\title{
Could waste fuel our cars?
}

\author{
James Browne
}

School of Engineering, UCC

\section{Introduction to waste in Ireland}

We are all familiar with the old saying of, "waste not, want not"; however, waste is an inevitable outcome of human activity. It is also clear that there is a direct link between economic development and increasing waste production. As people of the technology era, we as a society generate quite a staggering quantity of rubbish, more formally referred to as municipal solid waste (MSW).

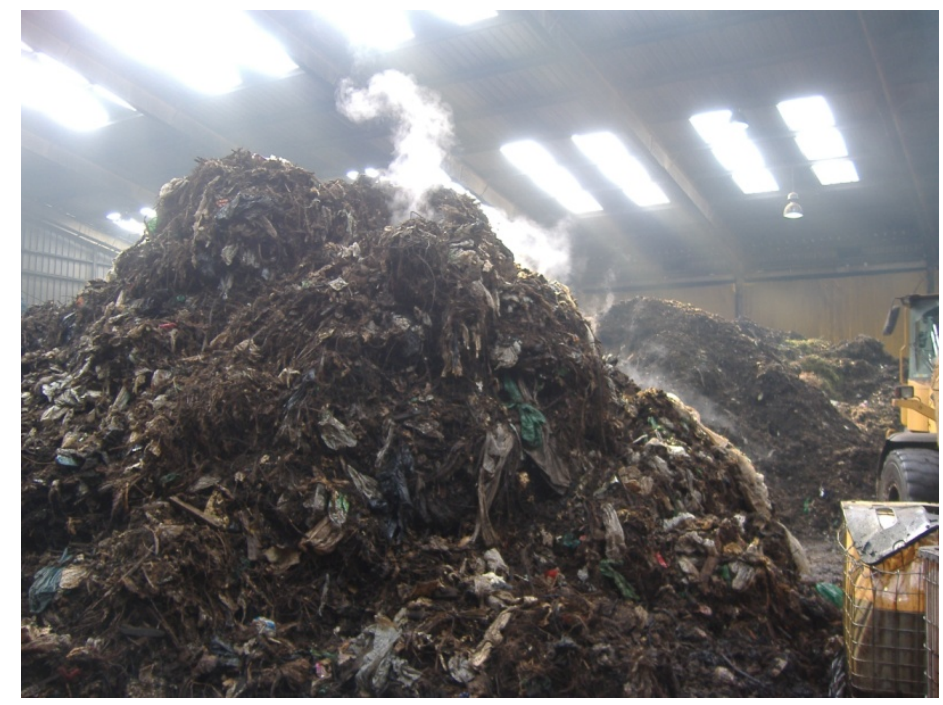

Figure 1: Biodegradable municipal waste

Currently, waste management is a hot topic in Ireland, with recent controversy over the proposed 600,000 tonne per annum municipal waste incinerator at Poolbeg, Dublin and also the controversial High Court ruling over waste ownership and collection in Fingal, Co. Dublin. It is fair to suggest that there is a lack of certainty and clarity with regards to implementing Ireland's waste management strategy. In the past, waste management was not considered a priority. However, over the past 20 years, this situation has changed dramatically, and waste management is now a top priority at National and European level.

\section{Biodegradable municipal waste}

Biodegradable municipal waste (BMW) is municipal waste that is capable of undergoing decomposition either in the presence of oxygen (aerobic degradation) or in the absence of 
oxygen (anaerobic degradation). BMW comprises of food and garden waste, paper, cardboard, certain textiles and wood. However, it is the food and garden waste, often referred to as the organic fraction of municipal solid waste (OFMSW), which presents the greatest environmental hazard, due to its fast rate of degradation and resulting by-products. In Ireland, about $65 \%$ of municipal waste is biodegradable, with OFMSW accounting for approximately $40 \%$ of this amount. Paper and cardboard account for about 54\%, while textiles and wood made up the remainder.

\section{Pollution from Waste}

As the environmental damage resulting from increased waste production and over reliance on landfill became more apparent, the EU moved to encourage the diversion of biodegradable waste from landfill. The EU Landfill Directive (1999) set out ambitious targets for member states to reduce the quantity of bio-waste going to landfill every year up to 2020 . Ireland has a target of 60\% reduction of bio-degradable waste by 2020 based on 1995 levels.

According to the environmental protection agency (EPA), approximately 2 million tonnes of MSW was landfilled in 2009. Although this figure has fallen somewhat, mirroring the fall in the economic growth, it is predicted that a return to growth will see an increase in waste generation once again. In order to reduce the harmful effects on the environment and to meet the ambitious waste diversion targets there is an urgent need to develop alternative waste management infrastructure to safely manage biodegradable waste.

\section{Could waste be a renewable energy source?}

To date, Ireland has almost exclusively relied on landfill as a means of managing MSW. While management of landfill sites has improved over recent years, it remains an undesirable treatment of biodegradable waste. In fact, the major problems associated with landfills are a result of OFMSW. Foul odour, water pollution from landfill run-off (leachate) and air pollution are all associated with the breakdown of organic waste buried deep within the landfill. As the garbage decomposes in the absence of oxygen (anaerobic conditions), bacteria present in the landfill produce a biogas which is approximately $50-60 \%$ methane, $40-50 \%$ carbon dioxide and small quantities of other gases such as water vapour and traces of hydrogen sulphide (the rotten egg smell).

Methane is reported as having a Global Warming potential of twenty times that of carbon dioxide. On the positive side, methane is also the major gas component of Natural Gas, which has an almost identical energy value $\left(38 \mathrm{MJ} / \mathrm{m}^{3}\right)$. This energy value is similar to that of a litre of diesel fuel. Some landfill operators have taken advantage of the stored energy potential in landfill gas and have installed gas generators to generate electricity. 
However, it is difficult to control and monitor gas production within landfills and the practise of utilising landfill gas is seen as a good short term solution to combat green house gas emissions, but ultimately landfill is the least desirable waste treatment option from an environmental viewpoint. The diversion of OFMSW from landfill presents an opportunity for generating a renewable source of energy.

\section{Anaerobic Digestion - Bio-gas Production}

The idea of using anaerobic digestion (AD) for treating potentially polluting wastes has been around for many years. In the late 1800s the street lamps around East London were powered by biogas from sewage sludge. However, the process was often prone to failure and was seen as an unreliable source of fuel. In recent years, great improvements have been made in understanding the biological activities in the $\mathrm{AD}$ process and have lead to the development of many biogas plants across Europe. By optimising the naturally occurring $\mathrm{AD}$ process in a purposely designed biogas plant, the potential energy from organic wastes can be recovered in the form of methane gas. Various organic wastes can be used, such as OFMSW, slaughter house waste, agricultural slurries and preserved/ensiled energy crops such as grass silage. Besides the production of energy in the form of biogas, $\mathrm{AD}$ also produces an organic fertiliser with lower pollution potential and significantly better availability of nutrients when compared to slurries. The biogas can be used to generate heat and electricity in a combined heat and power (CHP) unit, and electricity can be sold to the distribution grid or used on-site if needs be. An important consideration with using biogas for CHP is that up to $50 \%$ of the energy is transferred into heat, so having an adequate use for this energy is important for the efficiency of the system. Where a significant heat source is not required, upgrading biogas to biomethane may be a more effective method of energy transfer.

\section{Utilising Biogas for Transport}

Biogas can be upgraded to biomethane by eliminating the non-methane components such as carbon dioxide, hydrogen sulphide and other contaminants. The resulting biomethane is practically identical to natural gas and can be blended to give a cost-effective alternative to conventional transport fuels such as petrol and diesel. In countries such as Sweden, Germany and Switzerland, biomethane is used in addition to natural gas as a gaseous transport fuel in compressed natural gas (CNG) vehicles. Biomethane can also be injected into the gas grid reducing reliance on imported fossil fuels. The existing natural gas infrastructure allows for an efficient distribution system with the possibility to sell the biomethane anywhere on the gas grid.

A market for a competitive transport fuel in the form of a blend of biomethane and natural 
gas (BioCNG) has potential to bring environmental and economical benefits. There are now over 12 million CNG vehicles worldwide; this is set to rise due to cost efficiency and improved air quality. The use of compressed biomethane and blended BioCNG is also increasing, e.g., in Sweden there is approximately 17,000 CNG vehicles utilising a BioCNG fuel that contains more than $55 \%$ biomethane. The proportion of biomethane used in the gaseous fuel has increased over time and is set to further increase in the future.

\section{Renewable Energy in Ireland}

Although Ireland has made significant progress in generating renewable electricity, mostly through wind, it has proven difficult to meet the renewable energy targets for Heat and Transport. In the case of transport energy, this is partly because of the uncertainty over the sustainability of certain Biofuel crops and the food versus fuel debate. In addition, the cool, temperate, "mild" Irish climate and the limited availability of arable land does not allow for the mass production of high-yielding energy crops such as palm oil, sugar cane or cereals. It has been argued that Ireland's arable land (which accounts for only $9 \%$ of the total agricultural land mass) is already fully utilised for food and beverage production. However there is significant potential for renewable gas production from wastes and residues. The biodegradable fraction of municipal, commercial and industrial waste is now considered to be a renewable source of biomass. Biowastes such as animal slurries and waste products from abattoirs, breweries and agri-food industries could fulfil a significant portion of our energy needs. It is estimated that Ireland could easily supplement 3.5\% of transport energy from renewable gas from wastes, while the additional potential from surplus grassland $(2.5 \%$ of total grassland) could fulfil the $10 \%$ renewable energy target in transport for 2020. As Ireland currently imports approximately $98 \%$ of transport fuel, the potential contribution from indigenously produced biogas is significant. Transport energy accounts for approximately $40 \%$ of total energy use in Ireland, so finding sustainable, renewable sources of transport fuel would be hugely beneficial, both economically and environmentally.

\section{The future role of $A D$ in Ireland}

Although the benefits of using $\mathrm{AD}$ as a means of waste management and energy production have been highlighted by many, there are still obstacles in its development in Ireland and elsewhere. The introduction of a brown bin for organic waste in commercial premises and municipalities has provided a waste stream which is suitable for $\mathrm{AD}$ and biogas production. However the investment costs of an $\mathrm{AD}$ system are significant and in order to encourage investment, more certainty needs to be given to national and regional waste management strategy. 
$\mathrm{AD}$ is better suited to certain waste streams which degrade quickly, e.g., food waste; however, it is not effective for woody material, which takes far longer to breakdown under anaerobic conditions. $\mathrm{AD}$ can provide part of the waste management solution but other technologies such as composting and thermal treatment will also have to be utilised to divert the large quantities of biodegradable waste which are currently being sent to landfill.

Concerns about pathogen kill and the use of digestate as a fertiliser need to be addressed by further studies. The importance of agriculture to the Irish economy is hugely significant and so precautions are necessary where there is a risk of contaminating the food chain and the spreading of infectious diseases such as foot and mouth. This is particularly relevant to the movement and storage of agri-food wastes, animal slurry and former food stuffs.

Ireland has the potential to develop a significant biogas industry which would have multiple benefits to society and the environment. Further knowledge and expertise needs to be developed in all aspects of $\mathrm{AD}$. To this end the ongoing research into $\mathrm{AD}$ and biogas production is important for future development in Ireland. Current and future research will focus on biogas production from organic wastes and residues, AD biogas technology and modelling of biogas systems.

James Browne is a student at the Bio-energy group under the supervision of Dr. Jerry Murphy, Civil and Environmental Engineering Department UCC. The author would like to acknowledge Bord Gais Eireann and IRCSET for funding his research. 